\title{
Alcances de los Acuerdos de Paz
}

En la historia reciente de El Salvador, la firma de los Acuerdos de Paz del 16 de enero de 1992 es, probablemente, la única iniciativa de nación vivida por la sociedad salvadoreña, no tanto por su participación en la negociación, sino porque el resultado -el fin de la guerra- responde al clamor de la mayoría de la gente sin distingo de ningún tipo. A pesar de las diversas y hasta encontradas opiniones sobre el significado y los alcances de los acuerdos, veinte años después nadie duda de la trascendencia que tuvieron en la vida nacional.

El vigésimo aniversario de aquella trascendental fecha no pasó desapercibido para la sociedad salvadoreña. Abundaron los foros, hubo debates, se escribieron muchas páginas y se transmitieron numerosos programas de análisis. Las conmemoraciones fueron varias, entre ellas la promovida por el Gobierno central, cuyo acto principal se realizó en la aldea El Mozote, departamento de Morazán, donde treinta y un años antes, en diciembre de 1981 , se perpetró el mayor acto de violencia contra población civil cometida por agentes gubernamentales durante la guerra civil de El Salvador y también la considerada la peor masacre en el Hemisferio Occidental en tiempos modernos. La Comisión de la Verdad, creada para investigar los hechos de violencia durante la guerra y auspiciada por la ONU, estimó, en 1993, que fueron asesinados 900 campesinos, entre ellos cientos de niños, en El Mozote y los cantones aledaños.

La conmemoración de los veinte años del fin de la guerra civil dibuja un paisaje que resulta un marco idóneo para analizar la actual situación de la sociedad salvadoreña.

\section{Dos décadas después el país sigue polarizado}

En las muchas valoraciones vertidas sobre los acuerdos con ocasión de su vigésimo aniversario, el gran consenso es que -como ya se dijo- respondieron al clamor generalizado del pueblo salvadoreño. Efectivamente, el mayor logro de los acuerdos fue poner fin a doce años de guerra civil. En eso coincidieron casi todos los generadores de opinión y los propios firmantes de los Acuerdos de Paz.

Dicho lo anterior, hay que añadir la constatación de las notables discrepancias en la apreciación del significado y el legado de los Acuerdos de Paz. Que veinte años después de su firma el país sigue polarizado se hace evidente en las opiniones contrapuestas. Destaquemos tres de ellas. 


\section{"Se cumplió todo" versus "se cumplió casi nada"}

Para algunas personas y sobre todo para los firmantes, todo lo que se trazaron los acuerdos se cumplió en términos generales. Esta afirmación la sustentan básicamente en que, en 1997, la ONU declaró oficialmente que los acuerdos se habían cumplido con una nota sobresaliente. Butros ButrosGhali, secretario general de Naciones Unidas, dio por finalizado el proceso de paz en El Salvador, señalando que, si bien era cierto que no todos los acuerdos se habían cumplido en su totalidad, el grado de cumplimiento era aceptable. En el otro extremo, están los que sostienen que los acuerdos no se cumplieron y lo fundamentan básicamente en la constatación de que el país sigue con los mismos problemas de antes de la

Resulta muy curioso que a los mismos firmantes de la paz se les haya extraviado en el baúl de los recuerdos el texto mismo de lo que acordaron, pese a las intensas y muchas jornadas que supusieron casi dos años de negociación. guerra y, por tanto, no cambió porque los acuerdos no fueron cumplidos.

\section{"Los acuerdos solo querían terminar con la guerra" versus "pretendían mucho más"}

En términos generales, algunos firmantes de los acuerdos sostienen que la finalidad de estos era terminar con la guerra devolviendo a sus dos protagonistas al lugar que naturalmente les correspondía: la guerrilla del FMLN debía dejar las armas y entrar a la arena política; y la Fuerza Armada tenía que dejar la arena política y concentrarse en la defensa de la soberanía y el territorio nacional, conservando las armas. Por el contrario, otras personas opinan que los acuerdos pretendían no solo terminar la guerra, sino, entre otras cosas, propiciar la reunificación de la sociedad salvadoreña y superar las causas socioeconómicas que dieron origen al conflicto. El no cumplimiento de los acuerdos habría terminado con esta expectativa.

\section{"Lo de hoy es culpa de los acuerdos" versus "lo de hoy no tiene nada que ver"}

Finalmente, hay opiniones que sostienen que muchos males que aquejan a la sociedad salvadoreña en la actualidad tienen que ver con el incumplimiento de los Acuerdos de P. En esta dirección apuntan los que sostienen que la violencia galopante que acongoja a la sociedad salvadoreña se debe a la impunidad generada por el incumplimiento de las orientaciones de la Comisión de la Verdad. Y en la misma línea están los que afirman que no se hizo nada para cambiar el modelo económico concentrador y excluyente que dio origen al conflicto armado y que ahora expulsa a la población fuera del país o la lanza a los tortuosos caminos de la delincuencia.

Frente a esta apreciación, se encuentran las opiniones que sostienen que los de ahora son problemas distintos y que responden a otro contexto nacional $e$ internacional y que en absoluto tienen que ver con el cumplimiento o no de lo establecido hace veinte años. 


\section{¿Con qué lentes hay que valorar los Acuerdos de Paz?}

Aunque no se diga de manera explícita y no parezca tan obvio, la polarización de las opiniones, sobre todo en torno a los alcances de los Acuerdos de Paz, obedece, en gran medida, a la mirada a posteriori con que se analizan. Muchos de las consideraciones sobre el legado de los acuerdos se hacen desde la perspectiva de lo que en la realidad salvadoreña dieron de sí y no sobre lo que plantearon en su momento. Es decir, se juzga la potencialidad de los acuerdos con base en la realidad que tenemos veinte años después. A juzgar por sus declaraciones y opiniones, resulta muy curioso que a los mismos firmantes de la paz se les haya extraviado en el baúl de los recuerdos el texto mismo de lo que acordaron, pese a las intensas y muchas jornadas que supusieron casi dos años de negociación.

Para ser más justos con la historia e intentar acercarse más a la objetividad, el análisis del alcance de los acuerdos debe hacerse a la luz de lo que prometían, es decir, hay que analizar qué es lo que podían dar de sí y contrastarlos con la actualización que tuvieron en la realidad. De acuerdo con esto, se debe comenzar recordando que, en la primera jornada de negociación realizada entre las partes bajo la mediación del secretario general de la ONU, Javier Pérez de Cuéllar, en la ciudad de Ginebra el 4 de abril de 1990, se definió el marco general de la mesa de negociación y se plantearon los cuatro grandes objetivos que perseguían los Acuerdos de Paz:

1. Terminar el conflicto armado por la vía política al más corto plazo posible.

2. Impulsar la democratización del país.

3. Garantizar el irrestricto respeto a los derechos humanos.

4. Reunificar a la sociedad salvadoreña.

El contenido y los detalles de estos objetivos se desarrollaron y acordaron en las sucesivas jornadas que tuvieron como meta feliz los Acuerdos de Chapultepec, México, firmados el 16 de enero de 1992. Con base en estos objetivos y en las concreciones acordadas, se debe analizar el alcance que pudieron tener los Acuerdos de Paz en la realidad y en la sociedad salvadoreña, y-desde esta valoración-constatar lo que dieron de sí.

\section{Ni "se cumplió todo" ni "no se cumplió nada"}

Desde una visión general del alcance de los acuerdos, debemos afirmar que las dos posiciones extremas no hacen justicia a lo que se planteó al momento de la negociación. No es verdad afirmar que los acuerdos se cumplieron casi en su totalidad, como sostuvieron algunos firmantes de la paz, olvidándose quizá de todos los objetivos que definieron ellos mismos. Pero igualmente no hace honor a la verdad decir que no se cumplió nada. Si adoptáramos una escala para medir el cumplimiento (una especie de "cumplimientómetro") de los acuerdos, sin duda el que ocupa la vanguardia es el primero que se definió, el cual, como dijimos arriba, goza del consenso de la mayoría de valoraciones positivas expresadas públicamente. En el texto de los acuerdos, el énfasis mayor se puso, como debía ser, en poner fin a la 
guerra por la vía negociada, en consonancia con el clamor del pueblo salvadoreño y con las presiones internacionales que exigían una salida negociada para la guerra. Este había sido también el empeño de Ignacio Ellacuría desde los años ochenta.

En la misma jornada de Ginebra que dio el banderillazo de salida a la negociación, se definió como objetivo inicial "lograr los acuerdos políticos para el cese del enfrentamiento armado y de todo acto que irrespete los derechos de la población civil". Una vez conseguido lo anterior, se encaminarían a consensuar "el establecimiento de garantías y condiciones necesarias para la reincorporación de los integrantes del FMLN dentro del marco de plena legalidad, a la vida civil, institucional y política del país". Este acuerdo fue ratificado y profundizado en la segunda jornada de negociación realizada en Caracas el 21 de mayo de 1990 que definió la agenda general de la negociación. En dicha agenda, se definieron tres grandes temas: los dos primeros se correspondían con los diseñados poco más de un mes antes en Ginebra, y el tercero hacía referencia a los objetivos restantes (Acuerdos finales para la consolidación de los objetivos del Acuerdo de Ginebra y su verificación por las Naciones Unidas en lo que sea pertinente). En el mismo sentido, debe señalarse la celeridad con que el Acuerdo de México (27 de abril de 1991) propició las necesarias reformas constitucionales en la materia ante una Asamblea Legislativa que terminaba su periodo y cuya aprobación era indispensable para la continuidad de la agenda definida en Caracas.

Es decir, el fin de la guerra civil en El Salvador, calificado por la ONU como el proceso de paz más exitoso auspiciado por ella y que fue aplaudido por la comunidad internacional, se debió a que el mayor empeño de la negociación se centró en terminar con la guerra por la vía de la negociación. En esto tienen alguna razón los que sostienen que eso era lo que pretendían los Acuerdos de Paz, pero -como ya hemos visto y como lo expresan los mismos objetivos de los acuerdos--, no era lo único que se perseguía. Con la constatación de que los acuerdos perseguían algo más que terminar con la guerra, no se quiere subestimar el reconocimiento de que su mayor legado fue acabar con una sangrienta guerra a través de una vía pacífica. Pero aun en lo referente a este primer objetivo, no hubo un cumplimiento total. Recordemos dos ejemplos. Como parte del proceso de pacificación correspondía a la Fuerza Armada la depuración de sus elementos y la entrega de instalaciones para adecuarse al nuevo número de efectivos en tiempos de paz. El presidente Cristiani no solamente no depuró a muchos de los militares que contenía la lista de señalados para tal efecto, sino que los dejó activos hasta que les llegó el tiempo de retiro y fueron despedidos con honores. En los acuerdos de Chapultepec, como parte de la reducción de la Fuerza Armada, el Gobierno se comprometió a "la reconversión, devolución o supresión de instalaciones que dejen de ser usadas por la Fuerza Armada" (capítulo II, numeral 4, literal E). Veinte años después, la Fuerza Armada sigue utilizando todas las instalaciones que usó para la guerra, aunque pasó de contar con un aproximado de sesenta mil efectivos antes de la firma de los acuerdos a casi una sexta parte para el año 2008. Dicho sea de paso, el Gobierno del presidente Funes, argumentando las nuevas tareas de la Fuerza 
Armada, casi ha duplicado el número de efectivos que encontró al inicio de su mandato.

Pero no se pueden cerrar los ojos a otros cambios propiciados por los acuerdos suscritos entre aquel FMLN y aquella Fuerza Armada. En lo referente al segundo y tercer objetivo perseguidos por los acuerdos -impulsar la democratización del país y garantizar el irrestricto respeto a los derechos humanos-, hay que reconocer que el país ha avanzado en consonancia con lo que se plantearon los acuerdos. La creación de instituciones como la Policía Nacional Civil, la Academia Nacional de Seguridad Pública, la Procuraduría para la Defensa de los Derechos Humanos, la Defensoría del Consumidor, el Tribunal Supremo Electoral, el Consejo Nacional de la Judicatura, entre otras instancias, ha abonado a que el país siente las bases para el avance de la democratización y para mejorar el respeto a los derechos humanos. El Acuerdo de San José suscrito en Costa Rica el 26 de julio de 1990 es un despliegue detallado en la temática de los derechos humanos para garantizar las libertades fundamentales. Aparte de poner fin a la guerra, el logro de los acuerdos más destacado por diversos sectores durante la conmemoración del vigésimo aniversario hacía referencia a las libertades con que hoy cuenta el pueblo salvadoreño y que antes y durante la guerra civil eran sólo un sueño que parecía bastante lejano. En realidad, la negociación en materia de democratización y respeto

Personas ligadas a las fuerzas gubernamentales señaladas como responsables de graves violaciones a los derechos humanos, lejos de ser depuradas y sancionadas, han sido enaltecidas como héroes nacionales, rindiendo de esta manera culto a la impunidad.

a los derechos humanos no aspiraba a algo muy diferente de lo que cuenta cualquier país con un régimen medianamente democrático. El Acuerdo de San José enlista una serie de medidas que pretendían reconocer los derechos que ya estaban plasmados en el ordenamiento jurídico salvadoreño, así como en las declaraciones sobre derechos humanos aprobados por la ONU y la OEA.

Pero aun esta aspiración básica del respeto a los derechos fundamentales no se ha podido o no se ha querido cumplir dos décadas después de la firma de los acuerdos. Hoy la realidad nos golpea a la cara y nos dice que el derecho más sistemáticamente violado en el país es el derecho a la vida. Con más de cuatro mil homicidios anuales, la situación del país refleja que, aunque los acuerdos propiciaron la creación de instancias para el respeto a los derechos humanos, su desarrollo no ha sido el idóneo para lograr su cometido. No se puede hablar de respeto a los derechos humanos cuando hay un promedio de doce salvadoreños que pierden la vida de manera violenta todos los días y cuyos actores, en su inmensa mayoría, quedan en el anonimato o impunes. Es decir, en materia de derechos humanos, podemos afirmar que se cumplió, en gran medida, la letra de los Acuerdos de Paz con la efectiva creación de diversas instancias, pero el objetivo que se plantearon -respeto irrestricto de los derechos humanos- está lejos de alcanzarse si se niega el derecho que está a la base de todos los derechos: el respeto a la vida. Es posible que la gran mayoría de estas máximas violaciones a los derechos humanos no se puedan atribuir al Estado -como era el caso antes de 
la paz-, pero es innegable que este ha fallado y falla en su capacidad para impedirlas o castigarlas eficazmente.

En lo referente a la ola de violencia que vive en la actualidad El Salvador, el incumplimiento del cuarto objetivo de los acuerdos, probablemente, sí tenga que ver con la situación actual. Pero remitámonos de nuevo a los acuerdos.

\section{Acuerdos de Paz y situación actual}

Sin lugar a dudas, en nuestro "cumplimientómetro", el cuarto objetivo - lograr la reunificación de la sociedad salvadoreña- es el que obtiene la mayor reprobación. Para el alcanzar este objetivo, se definió como herramienta fundamental la creación de la Comisión de la Verdad que tendría -según el acuerdo de México- la misión de "investigar graves hechos de violencia ocurridos desde 1980, cuya huella sobre la sociedad reclama con mayor urgencia el conocimiento público de la verdad". En el acuerdo se menciona, explícitamente, que la Comisión tendrá en cuenta:

a. La singular trascendencia de hechos que ser investigados, sus características y repercusión, así como la conmoción social que originaron.

b. La necesidad de crear confianza en los cambios positivos que el proceso de paz impulsa y de estimular el tránsito hacia la reconciliación nacional.

Las tres personas nombradas por el secretario general de la ONU realizaron un intenso trabajo que incluyó la investigación de miles de casos de violaciones a los derechos humanos. El informe final de la Comisión que incluía las recomendaciones claves para transitar hacia la reunificación o reconciliación de la sociedad salvadoreña fue presentado públicamente el 15 de marzo de 1993. Cinco días después, el 20 de marzo, la Asamblea legislativa, a iniciativa del presidente del momento, Alfredo Cristiani, aprobó la Ley de Amnistía General mediante el Decreto N. ${ }^{\circ} 486$, que en la práctica sepultó el informe de la Comisión de la Verdad, bajo el lema de "perdón y olvido".

En estos tiempos de análisis de los acuerdos, se ha asegurado que se negoció la paz armada, pero la paz social nunca ha llegado a la sociedad salvadoreña. Algunas opiniones consideran que otros factores diferentes y posteriores a los acuerdos están en la raíz de la violencia actual y que por ello no se puede hablar de incumplimiento del cuarto objetivo de los Acuerdos de Paz. Pero la evidencia científica revela que el peor mensaje que se puede mandar a los delincuentes es el de la impunidad. Y eso fue lo que produjo la Ley de Amnistía.

En el más benevolente de los escenarios, el Gobierno de Cristiani se equivocó al equiparar el fin de la guerra con la reunificación de la sociedad, como si de una relación causal de matemática directa se tratara. Los Acuerdos de Paz consideraron que, al acabar con la guerra, una labor impostergable era trabajar por la reconciliación nacional como condición para consolidar la paz. Por eso, la reunificación de la sociedad formó parte de los cuatro 
grandes objetivos de los acuerdos. Pero la paz de las armas no significó reconciliación. Hoy es cada vez más reconocido que la Ley de Amnistía fue inconstitucional al beneficiar a funcionarios del mismo Gobierno que la decretó y no respondió a los parámetros universales en la materia, pues, bajo los lemas "perdón y olvido" y "borrón y cuenta nueva", se incluyeron crímenes de lesa humanidad, como la masacre del Mozote que hemos recordado arriba, desaparecimientos forzados e innumerables instancias de tortura. La medida cubrió con un manto de impunidad los peores crímenes cometidos contra población civil, dejando incólumes a sus hechores y cerrando así la puerta a la única posibilidad de conocer la verdad y dignificar a esas víctimas del conflicto. Personas ligadas a las fuerzas gubernamentales señaladas como responsables de graves violaciones a los derechos humanos, lejos de ser depuradas y sancionadas, han sido enaltecidas como héroes nacionales, rindiendo de esta manera culto a la impunidad.

El Salvador no vivió una posguerra tan necesaria en cualquier latitud después de un conflicto armado. Pasamos directamente de la guerra a la paz asumiendo que la reconciliación llegaba por un decreto. Veinte años después de la firma de los acuerdos, las heridas de la guerra siguen abiertas y lo único que puede cerrarlas es el conocimiento de la verdad y la dignificación de las víctimas. El acto del presidente Funes en el Mozote es un primer paso en el largo camino que hay que recorrer para que la reunificación de la sociedad sea una realidad. En este evidente incumplimiento del cuarto objetivo se refleja, con claridad, la polarización que vive todavía la sociedad salvadoreña. La sola posibilidad de derogar la Ley de Amnistía, como lo han pedido desde 1993 muchas instancias defensoras de los derechos humanos, provoca las reacciones más viscerales de los protagonistas del conflicto armado, que vuelven, veinte años después de firmada la paz, a hacer sonar los tambores de guerra si esta medida llegara a ejecutarse. Por el contrario, las víctimas guardan silencio en espera de que el velo de impunidad caiga y haga resplandecer la verdad para posibilitar la justicia y el verdadero perdón. No pocos conocedores de la realidad nacional consideran que la Ley de Amnistía le dio carta de ciudadanía a la impunidad de los criminales de guerra y eso, la impunidad, sí tiene que ver directamente con la situación de violencia que hoy padecemos los salvadoreños.

\section{¿Y los cambios económicos?}

El grueso del pueblo salvadoreño considera que los Acuerdos de Paz fueron algo trascendental para el país porque significó el fin de la guerra. Pero la mayoría de la población no conoció los detalles y los pormenores de los acuerdos. Una de las principales demandas sobre los incumplimientos de los acuerdos ha sido señalar que no pusieron las bases para empezar a resolver la situación económica de la mayoría de la población. Por eso, es conveniente decir una palabra al respecto. 
Si volvemos la mirada a los acuerdos, nos daremos cuenta de que sí hubo temas socioeconómicos que se abordaron, pero ninguna de las medidas acordadas perseguía ni podía alcanzar un cambio significativo en esta materia. En los Acuerdos de Nueva York del 25 de septiembre de 1991, en su parte VII, se abordó explícitamente el tema económico y social. Lo más radical de estos acuerdos en la materia era la dedicación de las tierras estatales mayores de 245 hectáreas (no declaradas reservas forestales) a campesinos y pequeños agricultores. El Gobierno se comprometía también, para tal fin, a comprar otras tierras que estuvieran en venta. Las otras medidas acordadas contemplaban la revisión de políticas para otorgar créditos al sector agropecuario, el estudio de medidas compensatorias para aliviar el costo social de los planes de ajuste estructural y la búsqueda de formas convenientes para la cooperación externa directa destinada a impulsar proyectos de asistencia y desarrollo de las comunidades. Finalmente, el Acuerdo de Nueva York postuló la creación del foro para concertación económica y social, con participación del Gobierno y de los sectores laboral y empresarial, a fin de resolver problemática económica y social.

Como puede verse, casi todas las medidas contempladas en los acuerdos eran paliativos que buscaban alivianar la carga sobre la población, pero nunca quitarla de sus espaldas. El único acuerdo que se encaminaba a buscar soluciones a los graves problemas económicos y sociales fue la creación de un foro económico y social (en círculos cercanos a los negociadores, se sostiene que este fue el mínimo resultado de una negociación paralela sobre los asuntos económicos entre Calderón Sol y Schafik Handal). Pero hubo incapacidad absoluta y, sobre todo falta de voluntad para darle seguimiento a este acuerdo. El foro murió sin dar ningún fruto.

Es decir, no se puede afirmar que los acuerdos se incumplieron porque no cambiaron la difícil situación económica de la población, pues los acuerdos no daban de sí para ello. Pero tampoco se puede afirmar que las pocas medidas que se plasmaron en la materia fueron cumplidas a cabalidad. La única que ofrecía potencialidad de cambio en materia económica y social fue hecha a un lado después de la firma de los acuerdos. Los costos de postergar soluciones estructurales a la situación económica y social los estamos viviendo con innegable dureza, veinte años después.

\section{Lecciones}

Como un preámbulo a los artículos que contiene ECA en este número, que abordan los Acuerdos de Paz desde temas específicos, queremos mencionar tres lecciones que nos dejan estos acuerdos y su posterior actualización en la realidad de El Salvador.

\section{La eficacia del diálogo}

La primera gran lección se refiere no tanto al contenido, sino al proceso que los hizo posibles. El fin de la guerra no supuso la imposición de una parte sobre la otra, no hubo vencedores ni vencidos. Se impuso el diálogo 
y la negociación. El proceso de negociación nos demostró que, por muy profundos y agudos que puedan ser los problemas y las diferencias, cuando hay diálogo y voluntad política siempre es posible encontrar caminos de solución. El cultivo de este espíritu haría mucho bien al país en las circunstancias actuales en las que solo con el concurso de todos los sectores de la sociedad se puede aspirar a salir adelante. En este vigésimo aniversario de la firma de la paz muchos sectores sociales y políticos coinciden en la necesidad de un esfuerzo similar al de los acuerdos para buscar salida a los grandes problemas del país. Plan de nación, proyecto de país, nuevos acuerdos de paz son nombres que expresan la misma necesidad de sentarse para entablar un diálogo sincero en busca de medidas que ayuden a El Salvador a salir de la crisis en que nos encontramos. Los evidentes signos de polarización que caracterizan a la sociedad salvadoreña hacen todavía más urgente el cultivo del espíritu de los acuerdos para poner, en el centro de la mesa y como prioridad, el bienestar de la sociedad en general por sobre los intereses particulares.

\section{Atacar la raíz de los problemas}

A pesar de la insistencia de opiniones aisladas -entre ellas, la de algunos firmantes de la paz- en poner las raíces del conflicto armado en factores externos de carácter ideológico, la historia y la realidad del país nos confirman que fueron causas de carácter interno las que provocaron una guerra fratricida, sin negar que ello fue ocasión para la injerencia de terceros que se alineaban a un lado o al otro en el contexto de la guerra fría.

En términos muy generales, dos grandes razones internas dieron origen a la guerra civil que padecimos: la primera fue una causa político ideológica al cerrarse las libertades fundamentales para toda posible disidencia política; la segunda fue una causa más de orden económico y social que obligaba a la mayoría de la población salvadoreña a solo sobrevivir ante la acumulación y concentración del patrimonio nacional en pocas manos. Los Acuerdos de $\mathrm{Paz}$ tocaron de frente la primera causa, la política, pero dejaron prácticamente intacta la segunda, la causa económico-social. Es innegable que, en materia de libertades políticas, hoy El Salvador ya no es el mismo que hace veinte años. Pero también es difícil negar que, dos décadas después, todavía tengamos una escandalosa concentración de la riqueza y una creciente desigualdad. Cualquier nueva iniciativa que pretenda enfrentar seriamente los problemas del país no debe obviar esta realidad económica y social que condiciona las otras esferas de la vida nacional.

\section{En el centro de la agenda deben estar las víctimas}

Como debía ser, la paz fue negociada por los dos protagonistas que hicieron la guerra. Y aunque los cuatro grandes objetivos que se plantearon en los acuerdos hacían referencia a toda la sociedad salvadoreña, el análisis de los textos nos revela que, en gran medida, los temas abordados hacían referencia directa a las dos partes negociadoras. Es decir, los acuerdos fueron producto de la negociación entre las dos cúpulas de las partes en conflicto, las cuales tuvieron entre sus prioridades los intereses de sus respectivos sec- 
tores. Las víctimas del conflicto y las víctimas del modelo excluyente responsable de la guerra no estuvieron en el centro de la mesa de negociación, sino que ocuparon un lugar marginal. Solo así se explica que la reunificación de la sociedad salvadoreña fue el acuerdo más incumplido de todos. Solo así se explica que no se haya tocado la situación económica y social, que ha sido el flagelo histórico de las grandes mayorías. No de otra manera hablaba la Conferencia de La Iglesia Católica en Puebla en las vísperas de la guerra:

Comprobamos (...), como el más devastador y humillante flagelo, la situación de inhumana pobreza en que viven millones de latinoamericanos, expresada, por ejemplo, en mortalidad infantil, falta de vivienda adecuada, problemas de salud, salarios de hambre, desempleo, desnutrición, inestabilidad laboral, migraciones masivas, forzadas y desamparadas, etc.

Cualquier iniciativa que pretenda desembocar en una agenda de nación debe poner en el centro de su discusión a las víctimas de la crisis económica y de la inseguridad que atravesamos. Las víctimas, entonces, deberían ser las protagonistas de unos nuevos acuerdos nacionales que busquen la paz social que emane de la justicia. 